\title{
Importance of Metabolism Variations in a Model of Extracorporeal Carbon Dioxide Removal*
}

\author{
S. Habran, Th. Desaive, Ph. Morimont, B. Lambermont and P.C. Dauby
}

\begin{abstract}
Extracorporeal $\mathrm{CO}_{2}$ Removal device is used in clinics when a patient suffers from a pulmonary insufficiency like Acute Respiratory Distress Syndrome and allows to decarboxylate blood externally. In this work, a model of the respiratory system coupled with such a device is proposed to analyze the decrease of $\mathrm{CO}_{2}$ partial pressure in blood. To validate the model, some parameters are estimated thanks to experimental data. Metabolism is a crucial parameter and we show that its time evolution must be taken into account in order to have correct $\mathrm{CO}_{2}$ partial pressure simulations in arteries and in veins.
\end{abstract}

\section{INTRODUCTION}

Acute Lung Injuries (ALI) or Acute Respiratory Distress Syndrome (ARDS) are still life threatening despite new strategies in mechanical ventilations $[1,2,3]$. In a clinical environment, a patient with ARDS is typically ventilated with low tidal volumes $(6 \mathrm{ml} / \mathrm{kg})$ and a driving pressure (maximal pressure) below $30 \mathrm{cmH}_{2} \mathrm{O}$. This technique, named as protective ventilation strategy, is important to reduce ventilator-induced lung injuries [4]. To increase the oxygen partial pressure, high inspiratory fraction of $\mathrm{O}_{2}$ is used and positive end-expiratory pressure (PEEP) allows to open alveoli. However, because of the low tidal volumes, the $\mathrm{CO}_{2}$ partial pressure is not sufficiently reduced, leading to hypercapnic acidosis, a deleterious condition for the global physiology including the lung and the pulmonary circulation. Indeed, hypercapnic acidosis induces pulmonary vasoconstriction and, consequently, pulmonary hypertension. Moreover, pulmonary hypertension can have severe repercussions on the right ventricle because of its high sensitivity to changes in pulmonary hemodynamics $[5,6]$. For these reasons, pulmonary hypertension and hypercapnic acidosis must be strictly controlled. In the case of hypertension, the driving pressure and the PEEP can be adapted on the ventilator [6]. For hypercapnic acidosis, a veno-venous ExtraCorporeal Membrane Oxygenator (vvECMO) is often used. When ARDS is not too severe $\left(\mathrm{PaO}_{2} / \mathrm{FIO}_{2}>100 \mathrm{mmHg}\right.$ [7], where $\mathrm{PaO} 2$ is the arterial partial pressure in $\mathrm{O}_{2}$ and $\mathrm{FIO}_{2}$ is the inspired oxygen fraction), the aim of the strategy is to decrease the $\mathrm{CO}_{2}$ partial pressure without being too invasive. In this case, the ECMO must rather be considered as a low flow extracorporeal $\mathrm{CO}_{2}$ removal device $\left(\mathrm{ECCO}_{2} \mathrm{RD}\right.$, see Figure 1).

To improve the knowledge and treatment of ARDS in intensive care patients, mathematical models of the

*Research supported by the belgian F.R.S-FNRS, PDR T.1058.14

S. Habran, T. Desaive P . Morimont and P. Dauby are with the GIGA-In silico Medecine and B. Lambermont is with the GIGA-Cardiovascular Science, University of Liège, Belgium. (Corresponding author: simon.habran@ulg.ac.be) respiratory system can be helpful in providing tools to characterize the gas exchanges efficiency in the lungs and in the $\mathrm{ECCO}_{2} \mathrm{RD}$.

The aim of the present work is to develop such a model, simple enough to be solved in real-time in a clinical environment. Our model is derived from the works of Batzel et al. [8] and Karbing et al. [9]. A pulmonary shunt is taken into account in parallel with the lungs and the modelling of the $\mathrm{ECCO}_{2} \mathrm{RD}$ consists in adding a second "lung compartment", which is perfused by a fraction of the systemic blood flow extracted in the inferior vena cava and reinjected in the atrium, after crossing the device (see Figure $1)$.

Figure 1. Extracorporeal $\mathrm{CO}_{2}$ removal device $\left(\mathrm{ECCO}_{2} \mathrm{RD}\right)$. $\mathrm{RA}$ is the right atrium and IVC is the inferior vena cava. Figure adapted from M.J. Murray and D.J. Cook [10]

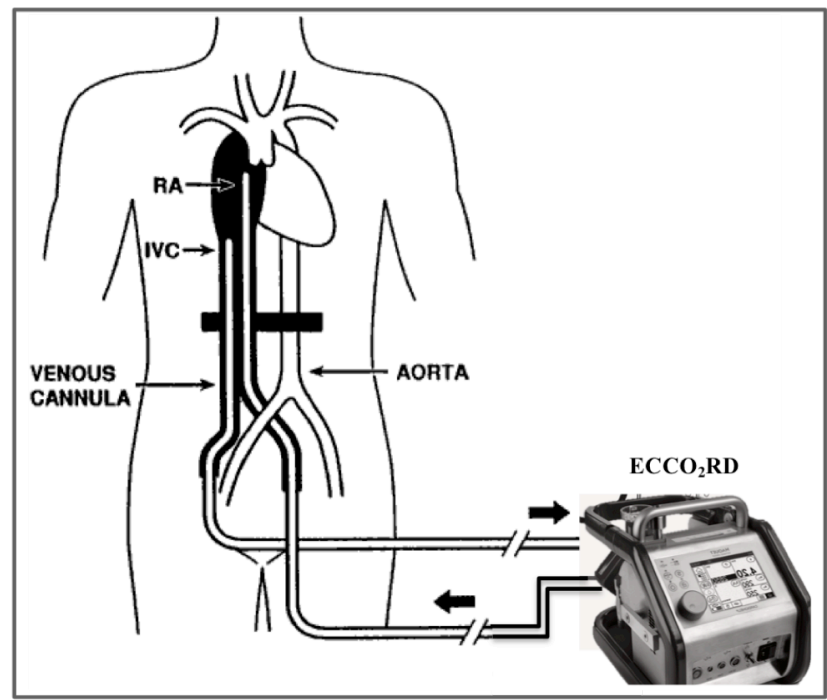

We estimate the parameters of the model and emphasize the role of the metabolism whose value cannot be assumed constant during our experiments. Taking into account its variations, we show that our model provides a good description of the $\mathrm{CO}_{2}$ time evolution and can thus be considered as an interesting tool that could help clinicians to improve the use of $\mathrm{ECCO}_{2} \mathrm{RD}$.

\section{METHODS}

In this study, the respiratory system assisted by an $\mathrm{ECCO}_{2} \mathrm{RD}$ is reduced to a small number of "compartments" (lumped parameter model). We consider two compartments for the respiratory system: the lung and the tissues. In addition, a third compartment is added to model the $\mathrm{ECCO}_{2} \mathrm{RD}$ (see Figure 2). 
Figure 2. Respiratory model assisted by an $\mathrm{ECCO}_{2} \mathrm{RD}$. The symbols $\mathrm{f}_{\mathrm{s}}$ and $\mathrm{f}_{\mathrm{d}}$ are respectively the pulmonary shunt fraction and the fraction of cardiac blood flow $\left(\mathrm{Q}_{\mathrm{c}}\right)$ which crosses the $\mathrm{ECCO}_{2} \mathrm{RD}$. The symbols $\mathrm{C}_{\mathrm{a}, \mathrm{i}}$,

$\mathrm{C}_{\mathrm{v}, \mathrm{i}}, \mathrm{C}_{\mathrm{d}, \mathrm{i}}, \mathrm{C}_{\mathrm{rv}, \mathrm{i}}$ and $\mathrm{C}_{\mathrm{l}, \mathrm{i}}$ denote respectively the blood concentrations for component $i$ in arteries, in veins, after the $\mathrm{ECCO}_{2} \mathrm{RD}$, in the right ventricule and in the lung.

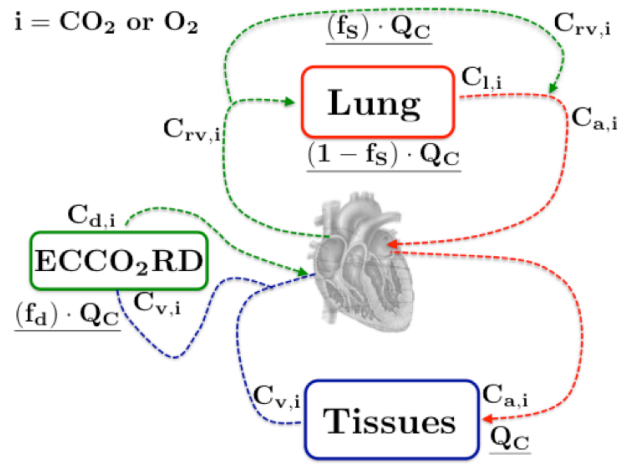

\section{A. Model of the respiratory system}

Our mathematical model of pulmonary gas exchanges and tissues gas exchanges is based on the work of Batzel et al. [8]. This model considers that diffusion of $\mathrm{O}_{2}$ and $\mathrm{CO}_{2}$ through the alveolar-capillary membrane is fast so that equilibrium can be assumed between the alveoli and the capillaries at the end of pulmonary capillaries. To include pulmonary gas exchanges abnormalities, additional parameters and additional equations are required. ARDS is a complex phenomenon and some authors describe this pathology by dividing the lung into 2 compartments to model ventilation/perfusion mismatch $[9,11]$. Since the identification of the parameters of these 2 compartments is not easy (and even impossible in our case with the available experimental data), we will use a simpler description. A pulmonary shunt and a dead volume will be used whose importance will determine the global quality of gas exchanges and which will thus allow to model lung injuries in a simple way. In the tissues, $\mathrm{O}_{2}$ is consumed and $\mathrm{CO}_{2}$ is produced by the metabolism and these quantities are considered as parameters of our model. Different estimations of these parameters are possible and will be presented below.

\section{B. Model of the $\mathrm{ECCO}_{2} \mathrm{RD}$}

The $\mathrm{ECCO}_{2} \mathrm{RD}$ is considered as a second lung compartment which takes a fraction of the systemic blood flow in the inferior vena cava and rejects the corresponding treated blood flow in the right atrium (see Figure 1). However, it is important to mention that the diffusion of $\mathrm{O}_{2}$ and $\mathrm{CO}_{2}$ across the synthetic membrane of the device is much slower than across the lung membrane. For this reason, the equilibrium between the gas and the blood in the device is usually not reached. Therefore, we have to model the diffusion of $\mathrm{O}_{2}$ and $\mathrm{CO}_{2}$ between the gas and the blood across the synthetic membrane [12]. We assume that the flows of air and blood are one-dimensional but have opposite directions (see Figure 3 and see for instance [13]).

Figure 3. $\mathrm{ECCO}_{2} \mathrm{RD}$ model

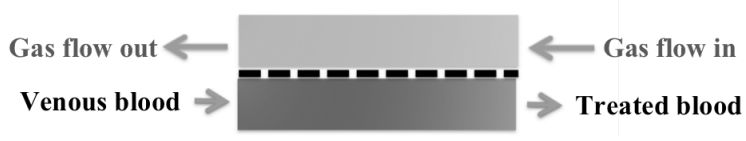

\section{Blood chemistry model}

In the blood, the relationships between partial pressures and total concentrations of gases are really complex. Indeed, $\mathrm{O}_{2}$ is dissolved in blood plasma and also complexed with hemoglobin while $\mathrm{CO}_{2}$ is dissolved in blood plasma, complexed with hemoglobin and subject to the hydratation reaction which couples $\mathrm{CO}_{2}$ and $\mathrm{HCO}_{3}{ }^{-}$. Since the $\mathrm{CO}_{2}$ partial pressure can vary very significantly, especially when a protective ventilation is used and when the medical device is switched on, we must consider the influence of the $\mathrm{pH}$ in blood plasma over the $\mathrm{O}_{2}$ haemoglobin saturation curve. To take this into account in our approach, the relation between the $\mathrm{O}_{2}$ concentration and the $\mathrm{O}_{2}$ partial pressure is based on the work of Grodins et al. [14]. The relations between $\mathrm{CO}_{2}$ concentration, $\mathrm{pH}$ in plasma and $\mathrm{CO}_{2}$ partial pressure are based on the work of Trueb et al. [15].

\section{Estimations of $\mathrm{CO}_{2}$ production and $\mathrm{O}_{2}$ consumption by the metabolism}

In a stabilized situation, the $\mathrm{CO}_{2}$ production $\left(\mathrm{MR}_{\mathrm{CO} 2}\right)$ can be estimated by:

$$
M R_{\mathrm{CO} 2}=Q_{c}\left(C_{v, \mathrm{CO} 2}-C_{a, \mathrm{CO} 2}\right),
$$

where $Q_{c}$ is the cardiac output, $\mathrm{C}_{v, \mathrm{CO} 2}$ and $\mathrm{C}_{a, \mathrm{CO} 2}$ are respectively the total venous and arterial $\mathrm{CO}_{2}$ concentrations (the venous concentration is measured in the inlet cannula of the $\left.\mathrm{ECCO}_{2} \mathrm{RD}\right)$. The $\mathrm{O}_{2}$ production $\left(M R_{\mathrm{O}_{2}}\right)$ can be determined similarly. Another estimation is possible by analyzing the gas expired out the $\mathrm{ECCO}_{2} \mathrm{RD}$ and gas expired out the ventilator :

$$
M R_{C O 2}=Q_{D} F_{D, C O 2}+Q_{L} F_{E, C O 2},
$$

where

- $F_{D, C O 2}$ and $F_{E, C O 2}$ are respectively the $\mathrm{CO}_{2}$ expired volume fraction out the $\mathrm{ECCO}_{2} \mathrm{RD}$ device and the volume fraction of end tidal $\mathrm{CO}_{2}$.

- $Q_{L}=\operatorname{Fr}\left(V_{T}-V_{D}\right)$ is the mean alveolar ventilation rate. $V_{T}$ is the tidal volume, $F r$ is the respiratory frequency and $V_{D}$ is the dead volume. For computing $M R_{C O 2}$, we assume that $V_{D}=0.3 V_{T}$ [16].

In our experimental setup, the $\mathrm{O}_{2}$ fractions in the ventilator and in the extracorporeal device are not available. Consequently, we will assume that $M R_{\mathrm{O} 2}$ is equal to $M R_{\mathrm{CO} 2}$. Finally, note that standard rough estimations of $\mathrm{CO}_{2}$ production and $\mathrm{O}_{2}$ consumption can also be found in the literature with values around $7 \mathrm{ml} / \mathrm{min} / \mathrm{kg}$ [17].

\section{E. Experimental data}

Experiments were carried out on 6 pigs, with the approval of the Ethics Committee of the Medical Faculty of the University of Liège. Protective ventilation was introduced for the pigs and extracorporeal $\mathrm{CO}_{2}$ removal was used to decarboxylate the blood. Note that no true pulmonary insufficiencies were induced on the animals but adjustment of the parameters of the protective ventilation allows to mimic the impaired gas exchanges that take place in such situations.

Blood flow was measured with thermodilution technique $\left(\mathrm{PiCCO}^{\circledR}\right.$, Pulsion, Germany) and with an admittance pressure-volume catheter (Transonic, USA). Tidal volume, 
PEEP, $\mathrm{F}_{\mathrm{I}, \mathrm{O} 2}$, respiratory frequency and driving pressure were fixed by the ventilator. Arterial and venous blood samples were analyzed with a RapidPoint500 ${ }^{\circledR}$ (Siemens, Germany) during basal state, after the introduction of the protective ventilation and during the $\mathrm{CO}_{2}$ removal procedure. In our experiments, the blood flow through the extracorporeal device was successively set to 200,400 and $600 \mathrm{ml} / \mathrm{min}$, which is referred to as ECCO2RD 200, ECCO2RD 400 and ECCO2RD 600 in Figures 4 and 5.

Thanks to cardiac blood flow measurements, to analyses of blood samples in the arteries and given the parameters fixed by the ventilator, the pulmonary shunt can be estimated just before the $\mathrm{ECCO}_{2} \mathrm{RD}$ is switched on and we consider its value constant for the whole simulation.

\section{RESULTS AND DISCUSSION}

The results corresponding to 4 pigs are presented and discussed in this section. For the other 2 pigs, experimental issues occurred (cardiac arrest for pig 1 and blood clots in the cannula for pig 6), which made the analysis impossible in these cases.

\section{A. Metabolism determination}

For all pigs, some blood estimations of $M R_{\mathrm{CO} 2}$ obtained from equation 7 , and similar estimations of $M R_{O 2}$, were too low to be physiological (below $0.051 / \mathrm{min}$ ) and their values vary a lot for a same experimental state. On the other hand, gas estimations of $M R_{\mathrm{CO} 2}$ obtained from equation 8 were more stable and their values were always in a physiological range. For these reason, only equation 8 will be used from now on to characterize the evolution of metabolism. Figure 4 corresponds to pig 5 and describes the production of $\mathrm{CO}_{2}$ by metabolism as a function of time. This production decreases linearly, with a slope of $7 \cdot 10^{-4} 1 / \mathrm{min}^{2}$. Note also that since pig 5 weighs $29 \mathrm{~kg}$, and considering a standard specific metabolism production of $7 \mathrm{ml} / \mathrm{min} / \mathrm{kg}$ [19], a rough estimation of its $\mathrm{MR}_{\mathrm{CO} 2}\left(=\mathrm{MR}_{\mathrm{O} 2}\right)$ is around $0.203 \mathrm{l} / \mathrm{min}$, which is actually the order of magnitude of the experimental values given in Figure 4. For the other pigs, the results are similar to Figure 4 (a decrease of $M R_{\mathrm{CO} 2}$ around $7 \cdot 10^{-4} 1 / \mathrm{min}^{2}$ and an initial value of $M R_{\mathrm{CO} 2}$ around $0.271 / \mathrm{min}$ ). Finally let us mention that the decrease of metabolism in our experimental setting after switching on the $\mathrm{ECCO}_{2} \mathrm{RD}$ is probably mainly due to hypothermia induced by the absence of a heater in our device (see the example in Figure 4).

Figure 4. The $M R_{\mathrm{CO} 2}$ estimations and the decrease of temperature for the pig 5

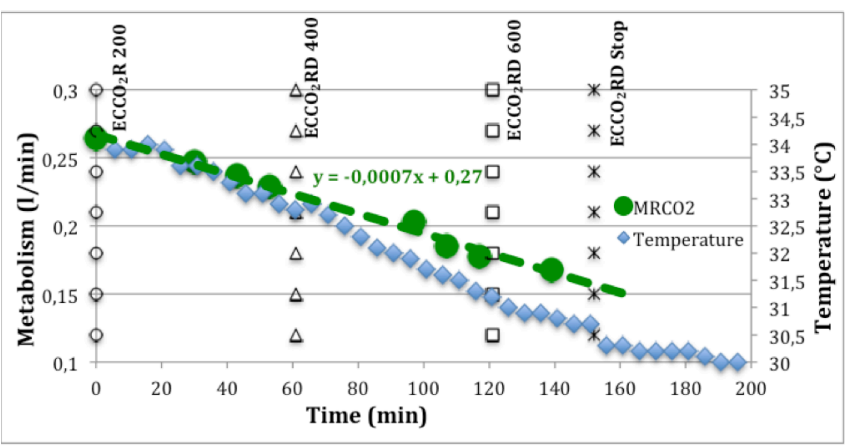

\section{B. Result of the model and comparison with experiments}

Using the values of $\mathrm{CO}_{2}$ production and $\mathrm{O}_{2}$ consumption given in the previous section and taking into account the influence of the $\mathrm{ECCO}_{2} \mathrm{RD}$, our model allows to determine the time evolution of the gas concentrations in the blood for pigs 2 to 5 . The corresponding results are presented in Figure 5, which shows the calculated curves describing the decrease of $\mathrm{CO}_{2}$ partial pressure in arteries and in veins. The figure also shows the corresponding experimental points (crosses). The solid lines correspond to time varying metabolims, while the dotted lines were obtained by considering constant $\mathrm{CO}_{2}$ gas production and constant $\mathrm{O}_{2}$ consumption rates. These constant rates can be estimated by $M R_{O 2}=M R_{C O 2}=W \cdot 7 \cdot 10^{-3} 1 / \mathrm{min}$, where $W$ is the weight of the pig. It is then interesting to note that the obtained values are found to be close to the corresponding mean measured values. The comparison of the solid and dotted lines with the experimental results clearly shows that a much better model is obtained when the time variations of metabolism are taken into account. This is particularly true at the most left and right parts of the 4 panels of Figure 5 , since at these times, the metabolism production rates for the 2 simulations are quite different from each other.

\section{CONCLUSION}

In this work, we have built and validated a mathematical model of the respiratory system assisted by an extracorporeal $\mathrm{CO}_{2}$ removal device. The predictions of the model are shown to be in good agreement with experimental data provided that the time evolutions of $\mathrm{CO}_{2}$ production and $\mathrm{O}_{2}$ consumption by metabolism are taken into account. The time evolution of metabolism must thus be described carefully in models of the respiratory system assisted by extracorporeal devices.

\section{ACKNOWLEDGMENT}

Financial support by F.R.S-FNRS (PDR T.1058.14) is cordially acknowledged.

\section{REFERENCES}

[1] M. Ragaller and T. Richter, "Acute lung injury and acute respiratory distress syndrome," Journal of Emergencies, Trauma and Shock, vol. 3(1), pp. 43-51, 2010.

[2] T.B. Enger, A. Philipp, et al., "Prediction of mortality in adult patients with severe acute lung failure receiving veno-venous extracorporeal membrane oxygenation: a prospective observational study," Critical Care, vol. 18(2), pp. R67, 2014.

[3] S. Klinzing, U. Wenger, et al., "External validation of scores proposed for estimation of survival probability of patients with severe adult respiratory distress syndrome undergoing extracorporeal membrane oxygenation therapy: a retrospective study," Critical Care, vol. 19(1), pp. $142,2015$.

[4] I. Vadasz, R.D. Hubmayr, et al., " Hypercapnia: A Nonpermissive Environment for the Lung," American Journal of Respiratory Cell and Molecular Biology, vol. 46(4), pp. 417-421, 2012.

[5] X. Represse, C. Charron and A. Vieillard-Baron, " Right ventricular failure in acute lung injury and acute respiratory distress syndrome," Minerva anestesiologica, vol. 78(8), pp. 941, 2012.

[6] X. Represse, C. Charron and A. Vieillard-Baron, “ Une approche moderne de la ventilation dans le syndrome de détresse respiratoire 
aiguë: laissez le ventricule droit respirer !," Réanimation, vol. 23(2), pp. 366-371, 2014.

[7] N. Ferguson, E. Fan, et al.," The Berlin definition of ARDS: an expanded rationale, justification, and supplementary material," Intensive Care Med, vol. 38(10), pp. 1573-1582, 2012.

[8] J. J. Batzel, F. Kappel, et al., “ Cardiovascular and respiratory systems: modeling, analysis, and control” in SIAM, vol. 34, 2007.

[9] D. S. Karbing, S. Kjaergaardand, et al.,“ Minimal model quantification of pulmonary gas exchange in intensive care patients," Med Eng Phys, vol. 33(2), pp. 240-248, 2011.

[10] M. J. Murray and D. Cook, “ Cardiopulmonary Bypass: Principles and Practice (chapter 33)," in LIPPINCOTT WILLIAMS \& WILKINS, a Wolters Kluwer business, $3^{\text {rd }}$ edition, 2008.

[11] S.E. Rees, S. Kjærgaard, et al.," The Automatic Lung Parameter Estimator (ALPE) system: Non-invasive estimation of pulmonary gas exchange parameters in 10-15 minutes," Journal of clinical monitoring and computing, vol. 17(1), pp. 43-52, 2002.

[12] M. Walter, S. Weyer, et al.," A physiological model for extracorporeal oxygenation controller design," Conf Proc IEEE Eng Med Biol Soc, pp. 434-437, 2010
[13] O.A. Linares, W.E. Schiesser et al., "In silico ordinary differential equation/partial differential equation hemodialysis model estimates methadone removal during dialysis," Journal of pain research, vol. 8, pp. $417,2015$.

[14] F.S. Grodins, J. Buell and A.J. Bart,“ Mathematical analysis and digital simulation of the respiratory control system," DTIC Document, 1967.

[15] TJ Trueb, NS Cherniack, et al.," A mathematical model of the controlled plant of the respiratory system," Biophysical journal, vol. 11(10), pp. 810-834, 1971.

[16] S.T. Hinski, " Respiratory care clinical competency LAB MANUAL (chapter 23)," in ELSEVIER, 2014.

[17] C. Karagiannidis, K.A. Kampe et al.," Veno-venous extracorporeal $\mathrm{CO} 2$ removal for the treatment of severe respiratory acidosis: pathophysiological and technical considerations," Critical care, vol. $18(3)$, pp. 124, 2014.

Figure 5. Time evolution of calculated (curves) and measured (crosses) $\mathrm{CO}_{2}$ partial pressures in veins and in arteries for pigs 2 to 5 . Solid and dotted lines correspond respectively to time varying and constant metabolisms (symbols var. MR and cst. MR).

Pig 2

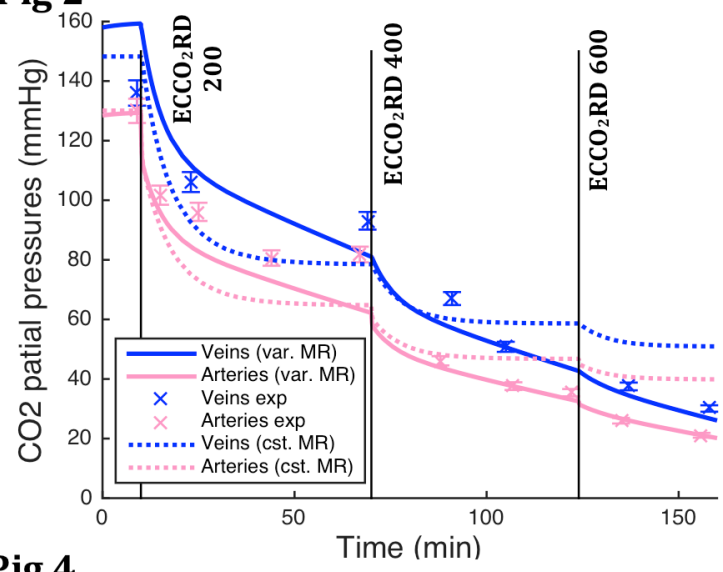

Pig 4

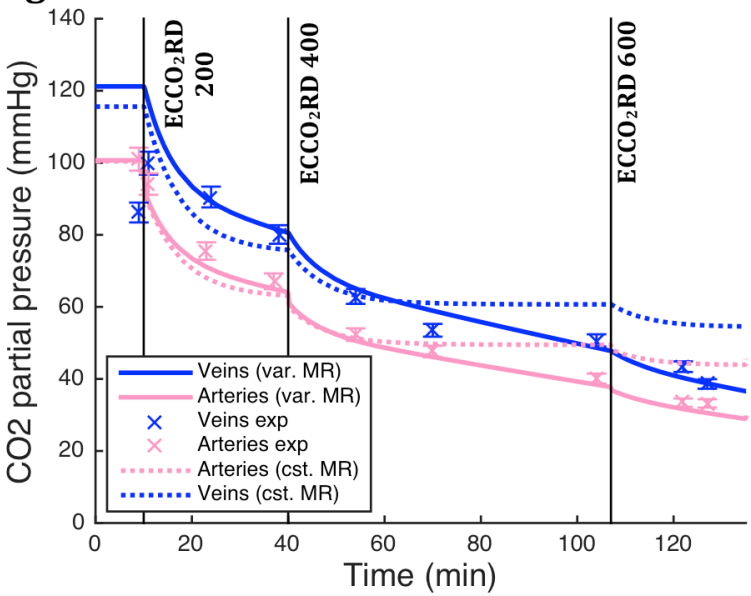

Pig 3
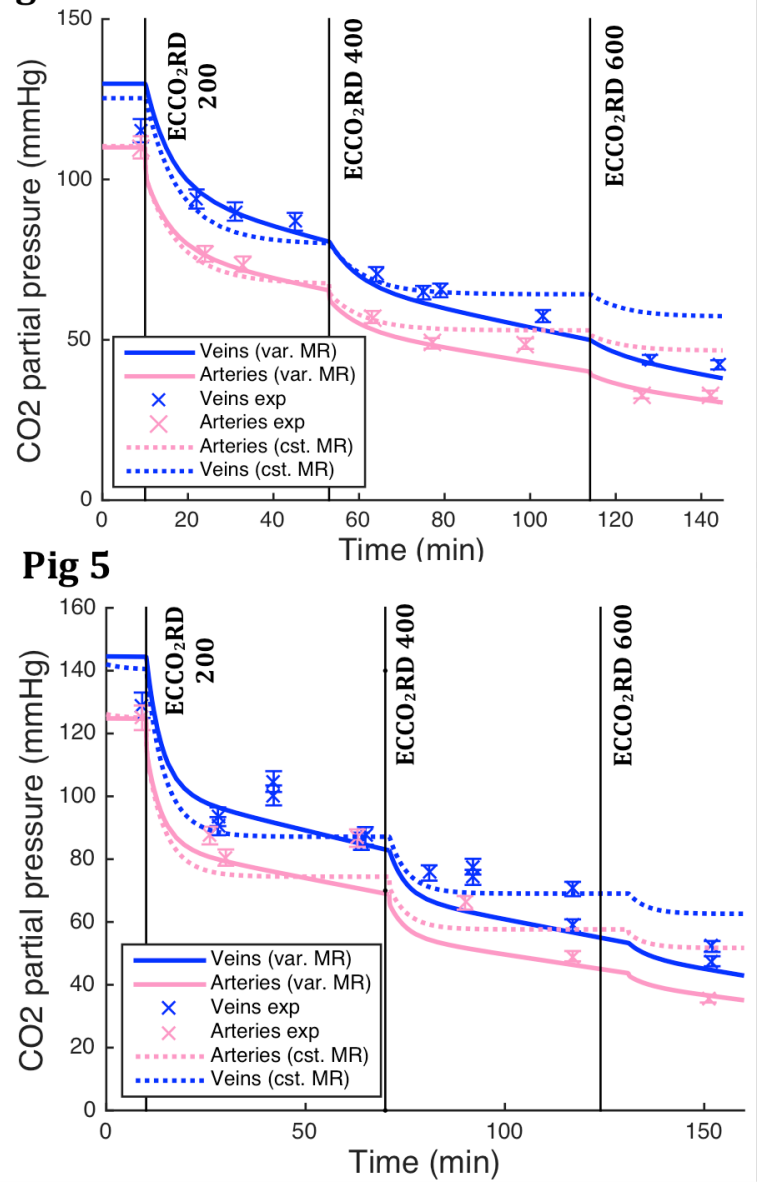